Jurnal Psikologi Teori dan Terapan

2016, Vol. 6, No. 2, 64-70, ISSN: 2087-1708

\title{
Harga Diri dan Konformitas dengan Perilaku Bullying Pada Siswa Sekolah Menengah Pertama
}

\author{
Retindha Ayu Ceilindri, dan Meita Santi Budiani \\ Program Studi Psikologi Universitas Negeri Surabaya
}

\begin{abstract}
The purpose of this research is to find out: (1) The correlation between self esteem and bullying behavior, (2) The correlation between conformity and bullying behavior, (3) The correlation between self esteem and conformity towards bullying behavior. The subjects of this research were 86 students on VIII grade of SMP Barunawati Surabaya, who are selected using population sampling technique. Data were collected using likert scales of self esteem, conformity, and bullying behavior. Data analysis technique of this research using multiple linier regression analysis. Results of this research are: (1) self esteem has a significant correlation towards bullying behavior with a negative correlation, can be seen from the significance value 0,000 and regression coefficientt $-0,526,(2)$ conformity has a significance correlation towards bullying behavior with a positive correlation that is shown from the significance value 0,003 and regression coefficientt 0,321, (3) Rsquare value 0,301 means that 30,1\% variations on bullying behavior is influenced of self esteem and conformity, the other variable that has a value of $69,9 \%$ is caused of other variable that is not measured in this research.
\end{abstract}

Keywords: self esteem, conformity, bullying behavior

\begin{abstract}
Abstrak: Penelitian ini bertujuan untuk menemukan: (1) Hubungan antara harga diri dengan perilaku bullying, (2) Hubungan antara konformitas dengan perilaku bullying, (3) Hubungan antara harga diri dan konformitas dengan perilaku bullying. Penelitian ini menggunakan metode kuantitatif korelasional. Subjek pada penelitian ini ialah 86 siswa kelas VIII SMP Barunawati Surabaya yang dipilih dengan menggunakan teknik sampel populasi. Data skala harga diri, skala konformitas dan skala perilaku bullying diperoleh menggunakan skala likert. Teknik analisis data dalam penelitian ini adalah uji analisis regresi linier berganda. Hasil penelitian menunjukan bahwa: (1) harga diri memiliki hubungan yang signifikan dengan perilaku bullying dengan arah hubungan yang negatif, dapat dilihat dari signifikansi sebesar 0,000 dan koefisien regresi $-0,526$. (2) konformitas memiliki hubungan yang signifiksn dengan perilaku bullying dengan arah hubungan positif yang dapat dilihat dari signifikansi sebesar 0,003 dan koefisien regresi sebesar 0,321. (3) nilai Rsquare sebesar 0,301 artinya sebesar 30,1\% variasi pada perilaku bullying dipengaruhi oleh harga diri dan konformitas, sisanya sebesar $69,9 \%$ disebabkan oleh variabel lain yang tidak diukur dalam penelitian ini.
\end{abstract}

Kata kunci: harga diri, konformitas, perilaku bullying

Masa sekolah adalah masa dimana hubungan pertemanan menjadi sangat penting. Menurut Hartup dan Stevens (dalam Baron \& Byrne, 2005), memiliki teman dapat berdampak positif pada harga diri, dan juga dapat membantu mengatasi stress. Namun, hubungan pertemanan juga dapat berujung pada efek negatif seperti pertengkaran,

Korespondensi tentang artikel ini dapat dialamatkan kepada Retindha A. Ceilindri melalui email: celin_dha@yahoo.com; atau Meita Santi Budiani melalui email: ita_peha@yahoo.com 
menarik diri, dan bentuk perilaku antisosial. Hubungan yang dilandasi senioritas, intimidasi, dan eksploitasi pada hubungan sosial remaja dapat menimbulkan dampak negatif. Tindak kekerasan dalam pertemanan tidak jarang menimbulkan korban luka bahkan meninggal. Salah satu kasus yang marak diperbincangkan adalah kasus bullying di salah satu SD di Bukittinggi Sumatra Barat. Korban adalah seorang anak berjenis kelamin perempuan. Siswi mengalami tindak pengeroyokan oleh beberapa teman sekelasnya laki-laki dan perempuan, mulai dari kekerasan verbal bahkan fisik, yaitu berupa pemukulan dan pelemparan benda (KPAI.go.id, 2014).

Di Pulau Jawa, kasus bullying juga terjadi beberapa kali, tepatnya di SMP 1 Tulungagung Jawa Timur dan Temanggung Jawa Tengah, keduanya terjadi kekerasan bullying verbal dan bullying fisik yang dialami siswa dikarenakan masalah senioritas dan pemerasan yang kemudian berujung pada pemukulan. (Liputan6.com, 2014). Sullivan (2004) menjelaskan ragam perilaku bullying yaitu secara fisik dan non fisik (verbal dan non-verbal). Bullying fisik berupa perilaku kekerasan yang dilakukan secara langsung terhadap korban, sedangkan bullying non fisik yaitu dengan menggunakan kata-kata mengolok, menghina, mengancam, dan memanggil dengan sebutan yang menyakitkan. Bullying berbeda dengan tindakan agresif lain yang melibatkan serangan hanya satu kali kesempatan, dan dalam waktu pendek. Bullying terjadi secara berkelanjutan dan dalam jangka waktu yang cukup lama dan tidak bisa dikatakan bullying apabila seseorang yang digoda tidak merasa terganggu.

Kasus percobaan bunuh diri akibat bullying sering dilakukan di lingkungan sekolah (Sejiwa, 2008). Perilaku bullying memiliki dampak berbahaya bagi anak, sesuai dengan penelitian yang dilakukan oleh Ratna (2005) menemukan bahwa 65\% kasus bullying yang terjadi di Yogyakarta ditemukan pada tingkat pendidikan SMP dan SMA. Data Komisi Perlindungan
Anak, saat ini kasus bullying menduduki peringkat teratas pengaduan masyarakat. Data dari 2011 hingga agustus 2014, KPAI mencatat 369 pengaduan terkait masalah tersebut, jumlah itu sekitar $25 \%$ dari total pengaduan di bidang pendidikan sebanyak 1.480 kasus (Kompas PA, 2014).

Rigby (2002) menyatakan bahwa sekolah menjadi titik awal terjadinya bullying dan tidak diragukan lagi bahwa bullying terjadi di sekolah dan menyebabkan beberapa anak menderita. Kecenderungan perilaku bullying disebabkan kurangnya pengawasan sekolah, ketidakpedulian teman-teman, dan kurangnya perhatian orang tua. Coloroso (2006) menjelaskan bahwa bullying akan melibatkan adanya ketidakseimbangan kekuatan, niat untuk mencederai, ancaman agresi lebih lanjut, dan teror.

Levianti (2008) berpendapat bahwa seseorang akan cenderung untuk melakukan bullying apabila pernah menjadi korban bullying dari orang yang lebih kuat, seperti kakak angkatan, teman yang berpengaruh atau lebih dominan dalam sebayanya. Orang lain akan ikut melakukan bullying karena menganggap perilaku tersebut wajar dan hal itu merupakan cara untuk menyesuaikan diri agar diterima lingkungan pergaulan. Penyesuaian diri yang paling mudah adalah dengan berperilaku mengikuti nilai dan aturan yang berlaku di lingkungan sekitarnya.

Menurut Anderson dan Carnagey (2004) ada faktor yang mempengaruhi perilaku bullying, yaitu faktor situasional atau lingkungan dan faktor personal, seperti tempramen dan harga diri. Menurut penelitian Rigby (2002) di sekolah menengah di Australia yang diidentifikasikan sebagai pelaku bullying adalah individu yang kurang kooperatif dalam berhubungan dengan individu lain atau kurang memiliki kecakapan sosial dan memiliki harga diri yang relatif rendah.

Penampilan fisik secara tidak langsung berkontribusi terhadap harga diri pada remaja (Harter dalam Santrock, 2007). 
Bagaimana individu berpenampilan akan menggambarkan citra dirinya serta identitas sosialnya. Lingkungan pergaulan juga memberikan banyak pengaruh bagi perkembangan remaja, seperti minat, sikap, pembicaraan, penampilan, dan perilaku, misalnya sebagian besar individu mencoba mengikuti apa yang dilakukan oleh anggota kelompok yang populer maka ia akan memiliki kesempatan besar untuk diterima dalam kelompok tersebut (Hurlock, 2004).

Harga diri merupakan evaluasi individu terhadap dirinya sendiri secara rendah atau tinggi. Penilaian tersebut terlihat dari penghargaan lingkungan terhadap keberadaan dan keberartian dirinya. Individu yang memiliki harga diri yang tinggi akan menerima dan menghargai diri-nya sendiri apa adanya. Harga diri men-cakup evaluasi dan penghargaan terhadap diri sendiri dan menghasilkan penilaian tinggi atau rendah terhadap dirinya sendiri. Penilaian tinggi terhadap diri sendiri adalah penilaian terhadap kondisi diri, menghargai kelebihan dan potensi diri, serta menerima kekurangan yang ada, sedangkan yang dimaksud dengan penilaian rendah terhadap diri sendiri adalah penilaian tidak suka atau tidak puas dengan kondisi diri sendiri, tidak menghargai kelebihan diri dengan melihat diri sebagai sesuatu yang selalu kurang (Santrock, 2007). Seseorang yang memiliki harga diri rendah akan cenderung mengikatkan diri dengan kelompok sebayanya dengan tujuan agar dirinya dianggap dan diakui di lingkungan kelompok mereka.

Menurut Coopersmith (dalam Mruk, 2006) salah satu ciri harga diri rendah yaitu merasa khawatir dan ragu-ragu dalam menghadapi tuntutan lingkungan dan menganggap dirinya sebagai orang yang tidak berharga dan tidak sesuai, sehingga takut gagal untuk melakukan hubungan sosial. Remaja akan menilai bagaimana dirinya dan apa yang mereka miliki, bagi remaja yang merasa bahwa dirinya kurang menarik dan kurang diterima dalam lingkungan, akan melakukan apa saja untuk memenuhi tuntutan lingkungan termasuk dengan mengadaptasi sifat-sifat orang lain atau kelompok untuk melihat apakah mereka cocok dengan dirinya, mereka juga memperhatikan bagaimana respon orang lain terhadap pengalamanya untuk mencocokan diri, sehingga mampu masuk dan diterima dalam suatu hubungan sosial.

Levianti (2008) menyatakan jumlah siswa yang banyak melakukan bullying dilakukan oleh siswa yang berpengaruh di kelas, maka siswa lain cenderung ikut melakukan tindakan bullying sehingga kelompok teman sekelas akan memberikan pengaruh kepada siswa untuk berperilaku sama dengan mayoritas teman dalam satu kelas atau kelompok. Perilaku tersebut disebut dengan konformitas.

Baron dan Byrne (2005) mendefinisikan konformitas sebagai sebuah bentuk pengaruh sosial, dimana individu mengubah sikap dan tingkah lakunya agar sesuai dengan norma sosial. Seseorang yang tidak sesuai dengan norma sosial akan merasa dikucilkan dalam lingkungan dan akan memiliki penghargaan yang rendah dari lingkungan dimana ia bersosialisasi. Hal tersebut yang membuat remaja memiliki kecenderungan untuk berkonformitas agar merasa diakui oleh lingkungan.

Perilaku negatif yang potensial untuk ditiru siswa adalah bullying. Bullying merupakan tindakan menyakiti orang lain yang lebih lemah, baik menyakiti secara fisik, kata-kata, ataupun perasaannya. Bullying berpeluang besar untuk ditiru karena perilaku negatif ini kemungkinan besar banyak dilakukan oleh siswa. Siswa cenderung melakukan bullying setelah mereka sendiri pernah disakiti oleh orang yang lebih kuat, misalnya oleh orang tua, kakak kandung, kakak kelas, ataupun teman sebaya yang lebih dominan. Siswa yang melakukan bullying banyak, atau bullying dilakukan oleh siswa yang berpengaruh di kelas, maka siswa lain akan ikut melakukan bullying, atau setidaknya menganggap bullying sebagai hal wajar (sikap positif terhadap bullying). 
Fenomena yang ada di Sekolah Menengah Pertama (SMP) swasta X di Surabaya adalah siswa melakukan perilaku bullying, paling banyak adalah tindakan bullying secara verbal yaitu me-manggil nama teman dengan nama julukan atau sering memanggil seseorang karena bentuk fisik yang dimiliki oleh anak tersebut, tidak jarang mereka membanding-kan dan mengejek kekurangan atau ke-lemahan. Ada setidaknya 3 siswi dalam satu kelas yang sering digoda dan dijadikan sasaran untuk diejek secara berulang-ulang ketika ia lewat diantara sekelompok siswa lakilaki ataupun perempuan sehigga menimbulkan perasaan tertekan dan menangis, bahkan ada beberapa siswi yang mengejek teman lain karena dianggap memiliki penampilan yang aneh atau fisik yang menarik perhatian mereka dari mayoritas siswi lainya hingga korban malu untuk pergi kesekolah. Bullying fisik seperti mendorong dan memukul dilakukan oleh beberapa siswa laki-laki kepada siswa yang lebih kecil yang biasanya dilakukan secara berkelompok. Ada pula siswa yang bertindak sebagai kelompok penguasa bagi teman yang lebih lemah dan memberikan ancaman untuk menuruti apa yang menjadi keinginkan kelompok, termasuk memalak dan menyuruh-nyuruh. Kelompok disini akan memiliki banyak pengikut yang akan sama-sama melakukan perilaku tersebut kepada teman yang telah menjadi sasaran sebelumnya.

Hasil wawancara awal dengan guru Bimbingan Konseling (BK) SMP X, diperoleh data bahwa 1 sampai 2 kasus perilaku bullying terjadi dalam setiap minggunya di sekolah tersebut dan hal itu biasa dilakukan oleh siswa. Guru olahraga SMP $X$ menjelaskan bahwa siswa juga sering melakukan bullying saat mata pelajaran olahraga kepada anak dengan kondisi fisik yang lemah dan terlihat kesulitan di beberapa cabang olahraga, sehingga dijadikan olok-olokan saat mata pelajaran olahraga berlangsung, teman lainya pun juga ikut mengoloknya hingga membuat anak memilih untuk tidak mengikuti olahraga.

Hasil wawancara kepada kepala sekolah SMP X, sering terjadi perilaku bullying yang dilakukan siswa yang ditujukan kepada anak yang memiliki kelemahan dalam hal fisik. Mereka sering mengolok kekurangan tersebut secara berulang dalam berbagai kesempatan dan menggodanya sehingga korban menangis dan melaporkanya pada guru BK, laporan seperti ini sering diterima oleh guru BK dan seringkali pelaku yang berkelompok telah mendapatkan beberapa sanksi. Dari wawancara yang dilakukan pada 6 siswa yaitu 4 laki-laki dan 2 perempuan di SMP $\mathrm{X}$, diperoleh data bahwa mereka mengatakan mudah melakukan bullying verbal karena mereka menganggapnya wajar dan teman lain juga melakukannya. Perilaku bullying sudah umum dilakukan dan hanya sebagai kesenangan tanpa memikirkan dampak dari perbuatannya bagi penerima bullying. Pelaku bullying justru akan semakin mengolok teman yang menangis ketika di-bully. Siswa laki-laki juga mudah mendorong siswa yang lemah dengan niat untuk menjahilinya sebagai lelucon di berbagai tempat.

\section{Metode}

Penelitian ini menggunakan metode kuantitatif korelasional untuk mengetahui hubungan antara harga diri dengan perilaku bullying dan konformitas dengan perilaku bullying. Populasinya adalah 86 siswa kelas VIII SMP swasta X di Surabaya. Pengambilan jumlah sampel menggunakan teknik sampling jenuh, yaitu mengambil semua dari jumlah populasi yang ada.

Instrumen yang digunakan dalam penelitian menggunkan skala harga diri, skala konformitas dan skala perilaku bullying dengan menggunakan model skala Likert. Sedangklan data yang diperoleh dianalisis menggunakan regresi berganda (multiple regression) yang bertujuan untuk melihat arah dan hubungan antar variabel yakni variabel harga diri dan konformitas 
dengan perilaku bullying. Analisis dengan regresi, dilakukan setelah uji persyaratan analisis dapat dipenuhi, yaitu meliputi uji normalitas, uji linieritas, uji multikolinieritas, dan uji autokorelasi.

\section{Hasil dan Pembahasan}

Berdasarkan uji analisis data yang telah dilakukan dengan menggunakan teknik analisis regresi linier berganda diketahui bahwa ketiga hipotesis diterima yang berarti ada hubungan antara harga diri dan perilaku bullying dengan $\mathrm{P}$ signifikansi sebesar 0,000 dan koefisien regresi sebesar $-0,526$, ada hubungan antara konformitas dengan perilaku bullying dengan $\mathrm{P}$ signifikansi sebesar 0,003 dan koefisien regresi sebesar 0,321, serta ada hubungan secara bersama-sama antara harga diri dan konformitas dengan perilaku bullying pada siswa kelas VIII SMP ' $X$ ' Surabaya dengan nilai signifikansi sebesar 0,000 , dan nilai Rsquare sebesar 0,301.

Berdasarkan analisis data yang dilakukan dengan menggunakan analisis regresi linier berganda diketahui bahwa ada hubungan secara bersama-sama antara harga diri dan konformitas dengan perilaku bullying. Hal ini dibuktikan dengan nilai signifikansi atau probabilitasnya sebesar $(\mathrm{p})$ $=0,000 \quad(\mathrm{p}<0,05)$. Variabel harga diri memiliki nilai koefisien regresi sebesar 0,526 . Variabel konformitas memiliki nilai koefisien regresi sebesar 0,321 yang berarti terdapat hubungan yang negatif untuk harga diri dan terdapat hubungan yang positif untuk konformitas, sehingga apabila harga diri rendah maka konformitas cenderung tinggi dan akan memunculkan perilaku bullying. Perilaku bullying muncul karena sebagian besar siswa bersifat positif pada bullying.

Anderson \& Carnagey (2004) menyatakan bahwa ada beberapa faktor yang mempengaruhi perilaku bullying, salah satunya harga diri. Menurut penelitian Rigby (2002) kebanyakan pelaku bullying di sekolah menengah di Australia adalah individu yang kurang kooperatif dalam berhubungan dengan orang lain atau kurang memiliki kecakapan sosial dan memiliki harga diri yang relatif rendah. Hal tersebut diperkuat dengan penelitian yang dilakukan oleh Widiharto dkk (2010) yang menunjukan bahwa ada hubungan yang signifikan antara harga diri dengan perilaku bullying, dimana anak yang memiliki harga diri positif akan memandang dirinya baik dan terhindar dari perilaku bullying, sebaliknya anak yang memiliki harga diri negatif akan memandang dirinya rendah dan mudah terpengaruh oleh lingkungan sehingga melakukan perilaku bullying sebagai salah satu bentuk adaptasi.

Coopersmith (dalam Ghufron dan Risnawita, 2010) menyatakan bahwa harga diri seseorang dapat menentukan bagaimana cara seseorang berperilaku di dalam lingkungannya. Peran harga diri dalam menentukan perilaku ini dapat dilihat melalui proses berpikirnya, emosi, nilai, cita-cita, serta tujuan yang hendak dicapai seseorang. Bila seseorang mempunyai harga diri yang tinggi, maka perilakunya juga akan tinggi, sedangkan bila harga dirinya rendah, akan tercermin pada perilakunya yang negatif. Individu yang merasa keberadaanya kurang berarti akan haus perhatian sehingga individu akan mencari dan mengadopsi perilaku yang menimbulkan perhatian bahkan menjadi sosok yang ditakuti untuk meningkatkan keberadaanya, salah satunya dengan mengadopsi perilaku bullying.

Hubungan antara harga diri dan konformitas dengan perilaku bullying diperkuat dengan penelitian Levianty (2008) yang menunjukan adanya hubungan signifikan antara konformitas dengan perilaku bullying. Hasil penelitian tersebut menjelaskan bahwa seorang yang berpotensi melakukan bullying adalah anak yang sebelumnya pernah sebagai korban dan penonton peristiwa bullying. Rasa takut akan dimusuhi oleh lingkungan membuat individu melakukan konformitas terhadap bullying, anak yang pernah menjadi korban 
ataupun menyaksikan bullying cenderung akan menjadi pelaku bullying, atau menganggap bullying sebagai hal yang wajar terjadi. Konformitas juga dapat membantu mengurangi terjadinya bullying apabila figur otoritas, populer, atau signifikan memiliki sikap negatif terhadap bullying, sehingga anggota di sekitarnya akan turut bersikap negatif terhadap bullying.

Santrock (2007) menyatakan konformitas terjadi apabila seorang individu mengadopsi sikap atau perilaku orang lain karena merasa didesak oleh orang lain baik desakan nyata atau bayangan yang tersirat. Desakan disini adalah untuk memenuhi harapan masyarakat atau kelompok mengenai suatu tindakan yang dianggap benar dalam berbagai situasi yang bertujuan menghindari kekacauan sosial dan agar dterima oleh lingkungan, maka siswa lain cenderung ikut melakukan tindakan bullying sehingga kelompok teman sekelas akan memberikan pengaruh kepada siswa yang berperilaku sama dengan mayoritas teman dalam satu kelas. Perilaku negatif tersebut berpeluang besar untuk ditiru karena perilaku ini kemungkinan besar banyak dilakukan oleh siswa atau sebagian besar siswa bersikap positif terhadap bullying.

\section{Simpulan}

Berdasarkan hasil penelitian dan analisis data yang dilakukan pada siswa kelas VIII SMP ' $X$ ' di Surabaya, dapat dibuktikan bahwa hipotesis penelitian ini diterima. Dapat disimpulkan bahwa terdapat hubungan yang signifikan antara harga diri dan konformitas dengan perilaku bullying secara bersama-sama.

Penelitian ini hanya berfokus pada harga diri, konformitas dan perilaku bullying yang mereka lakukan. Banyak lagi faktor yang mempengaruhi perilaku bullying. Bagi peneliti selanjutnya, diharapkan untuk dapat menggali lebih dalam faktor yang mempengaruhi bullying seperti pola asuh, lingkungan dan pengaruh sosial serta jenis bullying dan dampak perilaku bullying itu sendiri untuk dapat diteliti lebih lanjut. Berdasarkan hasil penelitian ini, disarankan agar ada kebijakan sekolah untuk meningkatkan harga diri positif siswa agar perilaku bullying siswa dapat berkurang.

\section{Daftar Pustaka}

Anderson, C.A \& Carnagey, N.L. (2004). Violent evil and the general affective aggression model. New York: Gilford Publication

Baron, R.A \& Byrne D. (2005). Psikologi Sosial, Jilid 2 Edisi Kesepuluh..(Alih Bahasa: Ratna Djuwita). Jakarta: Erlangga.

Coloroso, B. (2006). Penindas, Tertindas, dan penonton. Jakarta: PT Serambi Ilmu Semesta.

Coloroso, B. (2007). Stop bullying (Memutus Rantai Kekerasan Anak dari Prasekolah hingga SMU). Jakarta : Erlangga.
Djuwita, R, Riauskina., I dan Indira., S. (2005). "Gencet-gencetan" Di Mata Siswa/Siswi Kelas 1 SMA: Naskah Kognitif Tentang Arti Skenario dan Dampak "Gencet-Gencetan". Jurnal Psikologi Sosial 12 (1). (Online). http://ejournal.gunadarma.ac.id.

Diakses 23 Oktober 2014.

Destyan. (2014). Polisi selidiki kasus "Bullying" di SMP Tulungagung. (Online). http://www.antarajatim.com. Diakses pada 16 Desember 2014.

Ghufron, M. N \& Risnawita, R. (2010). Teori-teori Psikologi. Yogyakarta: ArRuzz Media Group. 
Hurlock. E. B (2004). Psikologi Perkembangan (Suatu Pendekatan Sepanjang Rentang Kehidupan). Alih Bahasa: Istiwidayanti \& Soedjarwo. Jakarta: Erlangga.

Levianti. (2008). Konformitas dan bullying pada siswa. Jurnal fakultas Psikologi 6 (1), 1-8. (Online). http://ejournal. esaunggul.ac.id/index.php/Psi/article/v iew/49. Diakses 6 November 2014.

Mruk, C. J. (2006). Self-Esteem Research, Theroy, and Practice. Toward a Positive Psychology of Self-Esteem. (3th ed.). New York: Springer Publishing Company.

Rigby, K. (2002). New Perspectives on Bullying. London: Jessica Kingsley.

Santrock, J. W. (2007). Life-Span Development. Perkembangan Masa Hdup (edisi kelima). (Alih Bahasa: Ahmad Chusairi). Jakarta: Erlangga.
SEJIWA, Tim yayasan. (2008). Mengatasi Kekerasan di Sekolah dan Lingkungan Sekitar Anak. Jakarta: PT Gramedia.

Sugiyono. (2010). Metode Penelitian Kuantitatif, kualitatif. Bandung: Alfabeta.

KPAI. (2014). Kasus Bullying dan Pendidikan Karakter. (Online). http:// www.kpai.go.id/berita/kpai-kasusbullying-dan-pendidikan-karakter/. Diakses tanggal 6 November 2014.

Sullivan, K., Cleary, M., \& Sullivan, G. (2004). In Secondary Schools: What It Loke and How To Manage It. (2nd .ed.). California: Corwin Press Inc.

Widiharto, C, Sanjaja, S \& Eriany, P. (2010). Perilaku Ditinjau dari Harga Diri dan Pemahaman Moral Anak. Jurnal psikologi Pendidikan, 1-16. (Online). http://eprints.unika.ac.id/1739/. Diakses tanggal 16 November 2014. 